\title{
Development of the Electromagnetic Induction Welding Device for Isolation Sheets
}

\author{
Kazuomi Deguchia, Kazuo Miyazawa ${ }^{b}$, Tohru Habac ${ }^{\mathrm{c}}$, Hiroshi Sakuraid, and Shigemasa \\ Tsubone $\mathrm{e}^{\mathrm{D}}$ \\ a Civil Engineering Div., Shimizu Corporation, Shibaura 1-2-3, Minato-ku, Tokyo \\ b Civil Engineering Div., Shimizu Corporation, Shibaura 1-2-3, Minato-ku, Tokyo \\ c Technical Development Dept., KFC Ltd., Shiba 2-5-10, Minato-ku, Tokyo \\ d Sales Dept., Carbofol Japan Co., Ltd., Shiba 2-5-10, Minato-ku, Tokyo \\ e Research and Development Dept., Seidensha Electronics Co., Ltd., Nishi-Nippori 2-2-17, \\ Arakawa-ku, Tokyo
}

\begin{abstract}
An electromagnetic induction welding device for isolation sheets has been developed with the aim of labor-saving, greater automation, and improved safety during the installation of isolation sheets in tunnels and other similar structures. This innovative development of the conventional sheet welding system is able to automatically locate welding points, disks through the sheet, heat them by electromagnetic induction, and apply pressure to weld the sheet to heated disks on the primary lining of a tunnel. Use of the device at actual worksites has eliminated a difficult and strenuous job, improved work efficiency considerably, and consequently enhanced the quality of work.
\end{abstract}

\section{INTRODUCTION}

It is critical to the safe and straightforward implementation of tunneling work that adequate drainage is provided for water which ponds behind the tunnel lining. Such water can exert considerable hydraulic pressure on the back of the tunnel lining, thus resulting in immediate attenuation of strength and later damage when post-completion changes in underground water distribution result in surface leakage. Water ponding behind the lining is a serious concern to those concerned with tunnel maintenance, as the resulting damage are often occurs after the tunnel enters service. Given that repairing such damage is extremely difficult once the tunnel is in use, it is critical, both technologically and economically, to incorporate adequate waterproofing and draining precautions in the design.

Further, tunnels carrying sewage or designed for rain water storage must be completely waterproofed to prevent leaks from within. The same is true of any tunnels constructed in built-up areas, where it is difficult to fit pumps for removing leakage because of restrictions on the pumping of ground water or because concessions have to be made to the requirements of sewage facilities.

Isolation sheets play a vital role in the waterproofing of tunnels, and are conventionally applied to the tunnel wall by hot air welding. Our new device, the Electromagnetic Induction Welding Device for Isolation Sheets, is a commercial labor-saving machine which uses a sensor to automatically locate welding points through the sheet and welds the sheet to the disk on the primary lining of the tunnel using an electromagnetic induction method. 


\section{COMPONENT AND OUTLINE OF THE DEVICE}

The conventional method of applying an isolation sheet to the primary lining surface of a tunnel entails turning over the edge of the sheet, so the previously attached disks can be seen, and then using the hands to make sure they are located correctly on the surface. The sheet is then welded to the heated disks using hot air supplied from an air blower. This is really tough work under extremely hot conditions and in a confined space side the wall, and yet it requires great skill. Our newly developed electromagnetic induction welding device automatically detects disk positions through the sheet and heats the adhesive on the disks using the action of electromagnetic induction before pressing the sheet into place. Conception of attaching the sheet by the electromagnetic induction device is shown in Figure 1, and the device is shown in operation in Photo 1.

The components of the device are outlined below:

(1) High-frequency current generator (Photo 2)

This generator produces high-frequency current from a mains power source to drive the electromagnetic induction device. The heating and cooling times can be set freely. The device also has a built-in alarm function.

- Power output:

$750 \mathrm{~W}$

- Output frequency:

$55 \pm 5 \mathrm{kHz}$

- Power supply:

- Weight:

AC $200 / 220 \mathrm{~V}$, single-phase, $50 / 60 \mathrm{~Hz}$

about $7 \mathrm{~kg}$

- Alarms:

welding failure, lack of cooling air, overheating, etc.

(2) Welding head (Photo 3)

The welding head performs two functions: it senses the positions of disks and heats the adhesive on the disks by the action of electromagnetic induction. The head is cooled with compressed air.

- Induction heating coil:

- Weight:

- Positioning precision: $\pm 3 \mathrm{~mm}$

$\emptyset 100 \mathrm{~mm}$

about $1.5 \mathrm{~kg}$

(3) Matching box (Photo 3)

This device amplifies the high-frequency current output from the high-frequency current generator to a predetermined value and supplies it to the coil in the welding head. The device has been made smaller and lighter by incorporating a control board for the positioning sensor.

- Weight: about $3 \mathrm{~kg}$

\section{ISOLATION SHEET LAYING METHOD AND FEATURES OF THE DEVICE}

\subsection{Isolation Sheet Laying Method}

The main work procedure, including sheet spreading, laying, and inspection is outlined below. The entire work process flow chart is shown in Fig. 2.

[Sheet spreading and positioning]

(1) The rolled sheet (consisting of a non-woven cloth and a sheet) is placed on the sheet spreading platform and unrolled down along the primary lining surface of the tunnel (Fig. $3)$.

(2) With the sheet hanging down near the wall, the lap with adjacent sheets is checked and adjusted.

(3) The entire sheet is lifted up until it makes firm contact with the wall (Photo 4). 
[Disk position sensing to sheet welding]

(1) The high-frequency current generator is turned on and appropriate heating and cooling times are set.

(2) The matching box is turned on.

(3) The welding head is moved over the sheet surface to locate a disk (Photo 5).

(4) After checking the disk position, the sheet is pushed against the disk by the welding head and the current generator is switched on.

(5) The welding head maintains pressure against the disk until the welding lamp goes off.

[Sheet-to-sheet sealing and welding] (Fig. 4)

(1) The sheets are checked for proper overlap and then adjacent sheets are pinched into the automatically traveling electro-thermal welder.

(2) The welding temperature and speed of the electro-thermal welder are set to ensure a good weld.

\subsection{Features of the Electromagnetic Induction Welding Device}

This new device has a number of remarkable features when compared with the conventional method of blow welding using hot air.

(1) Since the device carries out the heating and welding process from the reverse side of the sheet, limitations on sheet size are eliminated. This means that wider sheets can be used, with consequent reduction in the number of sheet-to-sheet welding points, and quality is enhanced.

(2) Welding disk locations can be sensed through the sheet, so simultaneous laying and welding of the unwoven cloth with the sheet is possible. This has improved work efficiency by about $30 \%$ as compared with the conventional method in which they are laid separately (Figs. 5 and 6).

(3) The heating time can be freely adjusted to suit the specifications of the isolation sheet in use. Thus the welding process requires no special skills.

(4) Use of this device has eliminated the use of hot air and the need for workers to take up unnatural postures. As a result, workers are liberated from stressful labor and can work in conditions of greater safety (Photo 6).

\section{APPLICATION EXAMPLE}

\subsection{Outline of Project Using the Device}

Project name: $\quad$ Trans-Tokyo Bay Highway, Ukishima South of Kawasaki

Tunnel outer diameter: $13.9 \mathrm{~m}$ Tunnel Construction Project, Phase 1 and Phase 2

Length:

$900 \mathrm{~m}$ (Phase 1) $+1,400 \mathrm{~m}$ (Phase 2)

Construction method: Slurry shield tunneling method

Construction term: July 1, 1992 to March 26, 1997

Site:

Kawasaki City, Kanagawa Prefecture, Japan

\subsection{Work Conditions}

In this tunnel, isolation sheets are being applied in two parts, upper and lower, because of various restrictions imposed on the shield tunneling work. These include the construction procedure adopted for the project, various engineering requirements, and the tunnel cross section, which is greater than normal. The lower half of the tunnel is lined first, followed by the upper half once the lower lining has been completed over a certain length. The upper and lower parts are then joined to form the circular lining. 
The lower half is lined with sheets measuring $3 \mathrm{~m}$ wide by about $9 \mathrm{~m}$ long. These are spread upward on both sides of the tunnel from the center of the tunnel bottom. The upper half lining consists of rolled sheets, each $3 \mathrm{~m}$ wide and about $22 \mathrm{~m}$ long, which are placed on the crest of the spreading platform and unrolled down both sides. Sheet clamping plates on the platform are raised up to bring the sheets into contact with the wall surface. As the sheets are raised, laps (of about $10 \mathrm{~cm}$ ) are ensured. To finish the lining, the electromagnetic induction welder is used to find disk positions through the sheet and the sheet is fixed to the wall by heating and welding (Photos 7 and 8 ).

Sheets are sealed and welded together with a conventional automatically traveling electrothermal welder. Where the upper sheets and lower sheets meet (with a triple lap), the sheet edges are chamfered and welded together along the axial direction by an electro-thermal welder (Photo 9).

The introduction of this new device enabled the use of $3 \mathrm{~m}$-wide sheets, compared with the maximum 1.5 to $2 \mathrm{~m}$ sheets which can be used with the conventional method using a hot air blower. The number of sheet sealing and welding points was also reduced by 30 to $50 \%$. In total, this system resulted in a reduced number of work steps and improved quality.

The overall efficiency of isolation sheet installation has also been improved by about $30 \%$ through the simultaneous laying of the unwoven cloth and the sheet. The conventional method required application of the unwoven cloth first.

\section{CONCLUSION}

Our newly developed electromagnetic induction welding device is a compact, easy-to-use machine that features an innovative combination of known techniques. Although technically not revolutionary, it appears to have achieved an almost revolutionary improvement, or rationalization, in isolation sheet laying work. It may seem relatively unexciting as compared with certain other remarkable achievements of automation and robotics, but the fact that a mere development of conventional ideas with some added twists can change conventional procedures so much should offer important clues to engineers' in their efforts to make technological breakthroughs despite constraints such as cost performance and practicality.

The next challenge facing the developers of this machine is the application of similar techniques to the sealing and welding of sheets to each other.

The authors would like to express their gratitude to all those who provided valuable advice and instruction, and who cooperated in the development of this device and its application to actual work sites.

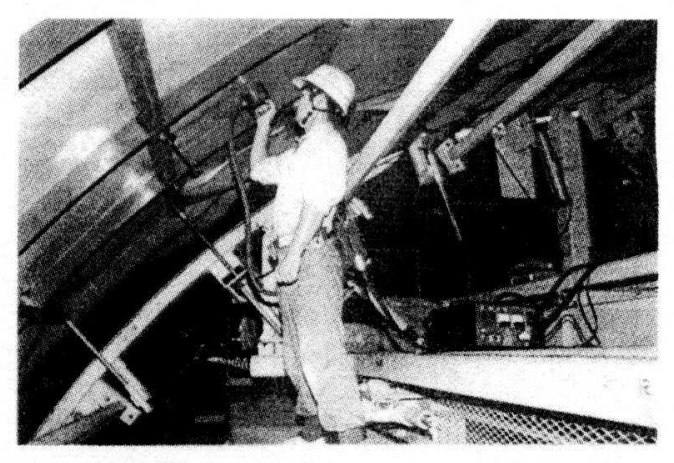

Photo 1 Welding with electromagnetic induction welder

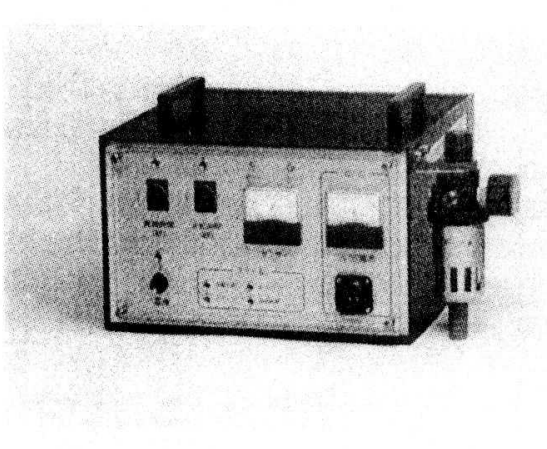

Photo 2 High-frequency current generator 


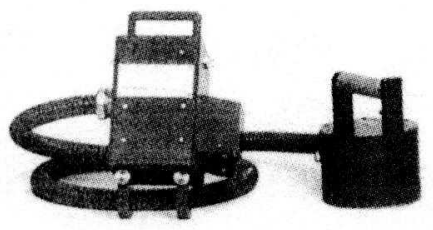

Photo 3 Welding head (right) and matching box (left)

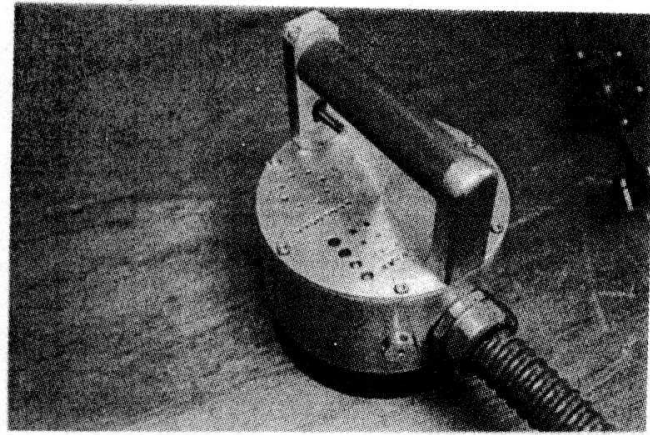

Photo 5 Welding head

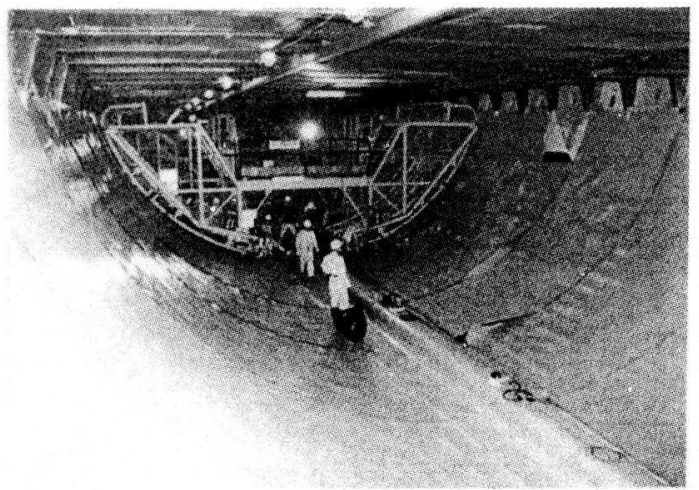

Photo 7 Lining lower half of tunnel

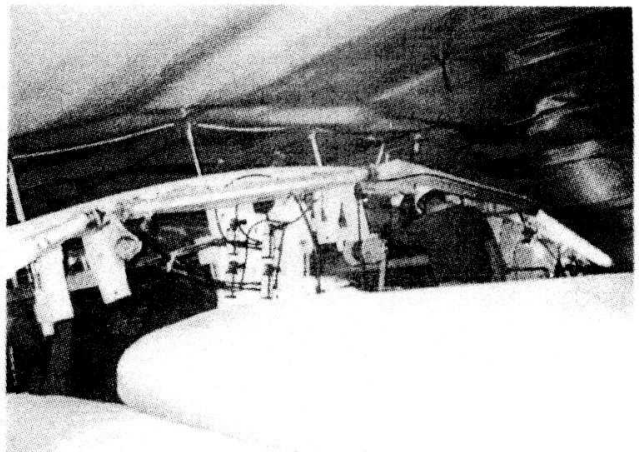

Photo 4 Lifting and clamping isolation sheet

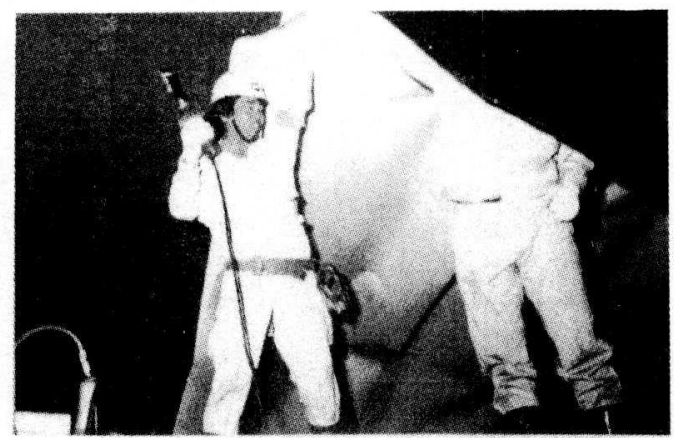

Photo 6 Welding by hot air blower

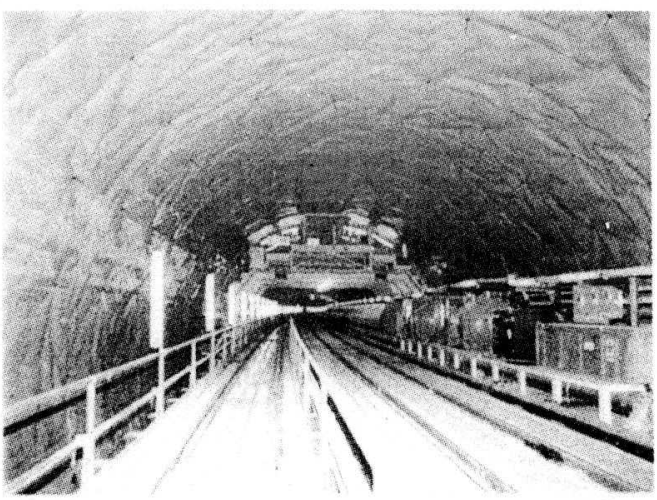

Photo 8 Lining upper half of tunnel 


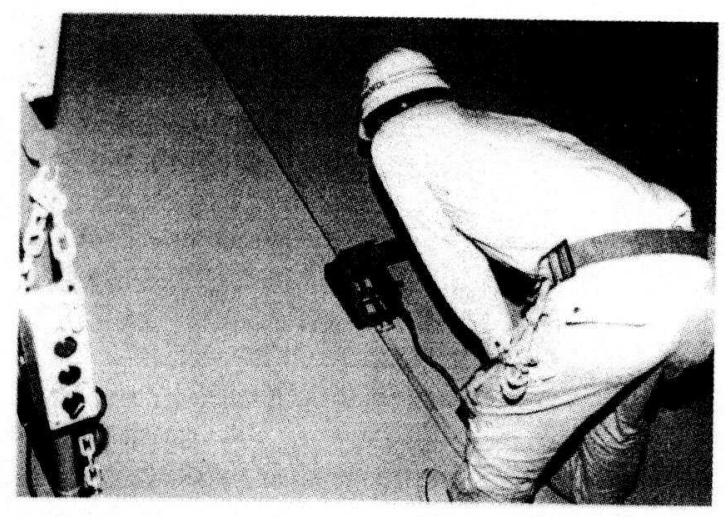

Photo 9 Sheet-to-sheet sealing and welding
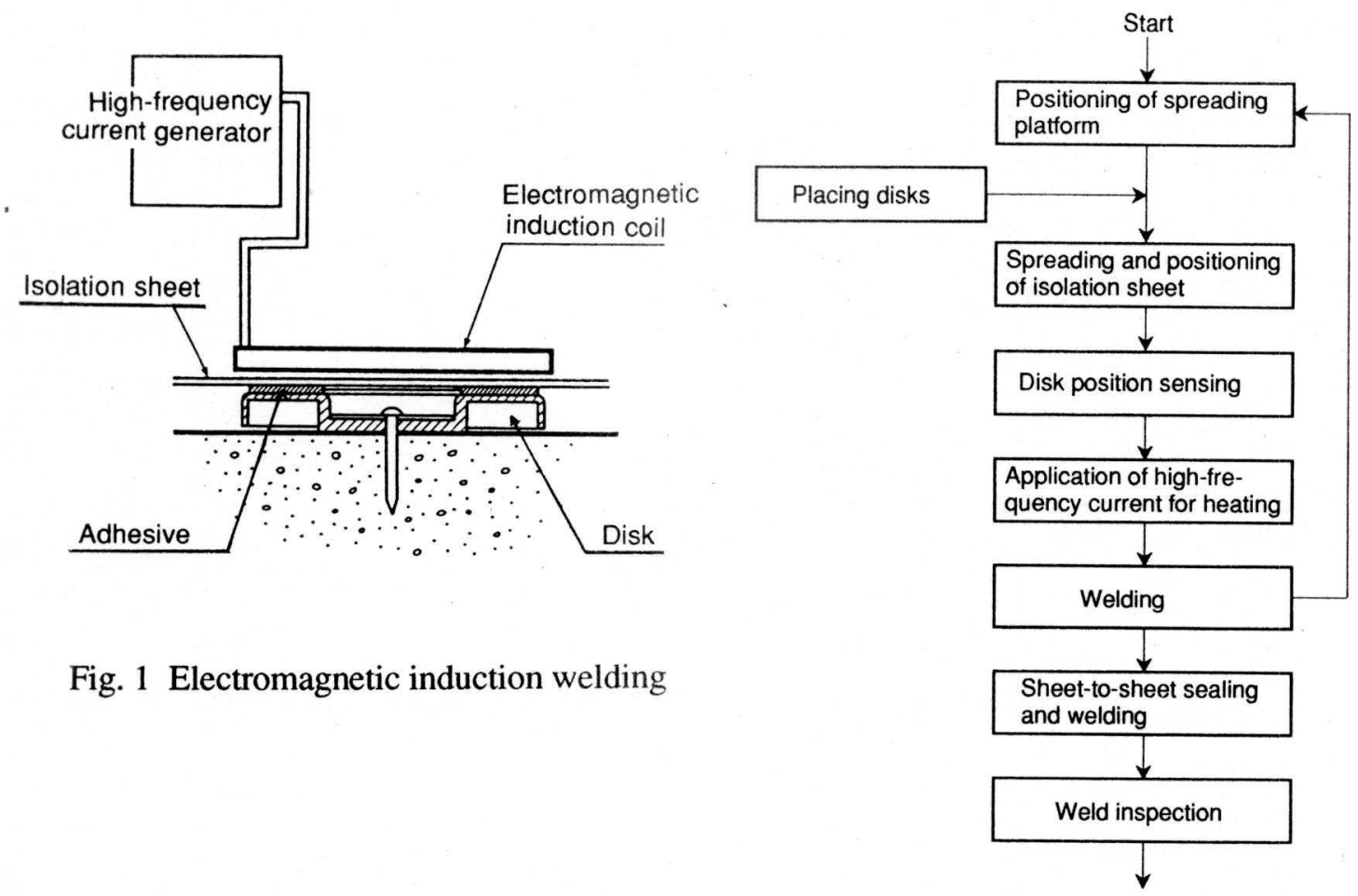

Relocation of spreading platform

Fig. 1 Electromagnetic induction welding

Fig. 2 Flow chart for isolation sheet laying and welding 


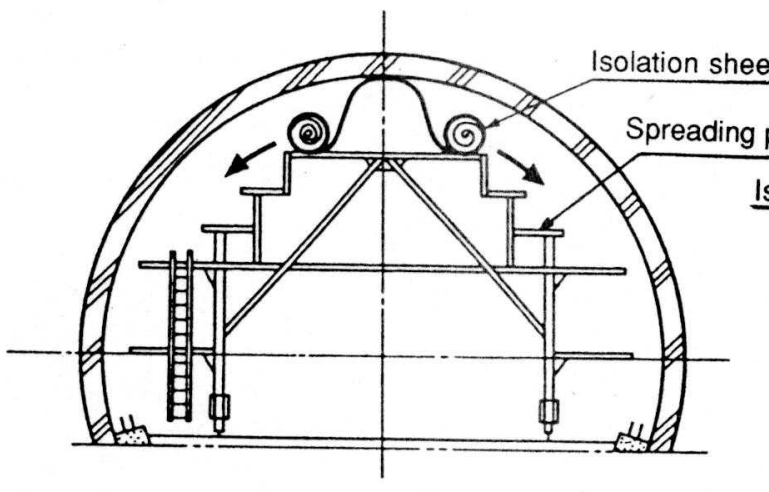

Fig. 3 Spreading the isolation sheet

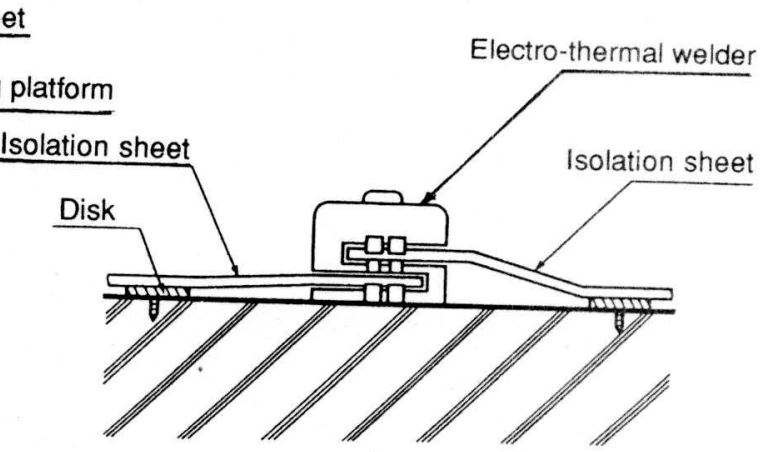

Fig. 4 Sheet-to-sheet sealing and welding

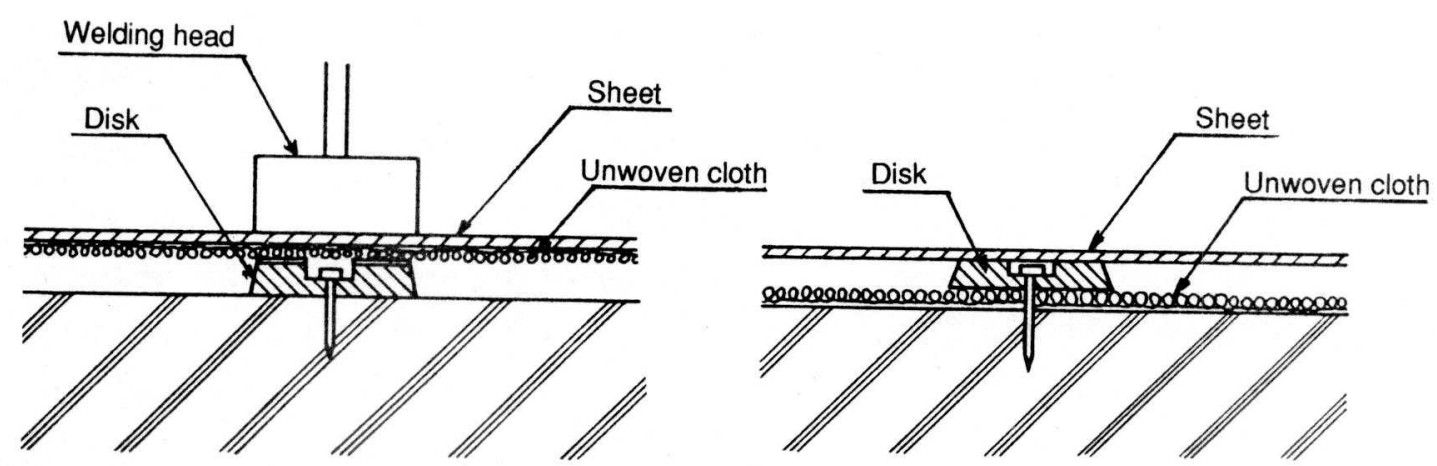

Fig. 5 Simultaneous laying

Fig. 6 Separate laying 